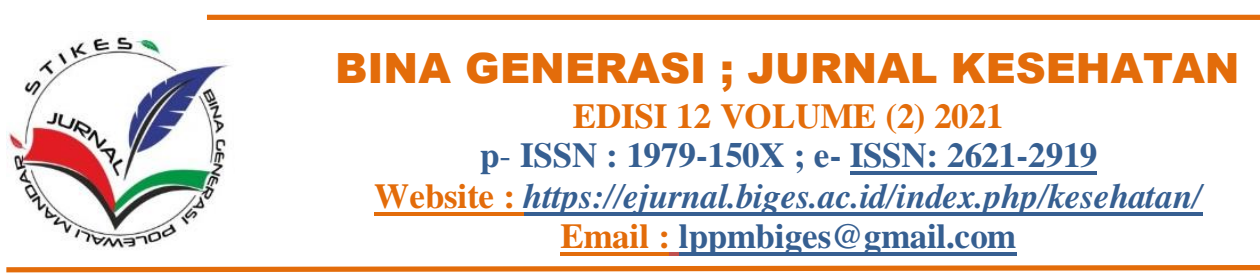

\title{
PERILAKU IBU DALAM STIMULASI TUMBUH KEMBANG BALITA USIA 0-6 BULAN SETELAH PEMBERIAN ANTICIPATORY GUIDANCE
}

\author{
Desi Trianita $^{1}$, Atik Pramesti Wilujeng ${ }^{2}$, Ninis Indriani ${ }^{3}$ \\ ${ }^{1}$ S-1 Kebidanan, Stikes Banyuwangi, Indonesia \\ ${ }^{2}$ D-3 Keperawatan, Stikess Banyuwangi, Indonesia \\ ${ }^{3} \mathrm{~S}-1$ Keperawatan, Stikes Banyuwangi, Indonesia
}

Keyword :

Mother's behavior, anticipatory guidance, growth, development

\begin{abstract}
The toddler period is a period of rapid growth and development in which children reach optimal development at this age. Families, especially mothers, have an important role in optimizing children's growth and development. This study aims to conduct maternal behavior in stimulating growth and development after being given anticipatory guidance with a group of mothers who were not given anticipatory guidance. The design that used the quasy experimental post test was only a non-equivalent control group, while the sample was 54 mothers who had infants 0-6 months, taken by purposive sampling technique. The results of the MannWhitney U statistical test showed that there was a mother's behavior in stimulating growth and development in the treatment group with a value of $\rho=0.000$. Assessment of mother behavior in stimulating growth and development is carried out by filling out a questionnaire. Anticipatory guidance is to provide guidance and assistance by health workers to parents of children, in this case the mother on how to care for and fulfill the growth and development needs of her child.
\end{abstract}

\section{PENDAHULUAN}

Pertumbuhan dan perkembangan yang dicapai pada masa balita akan menentukan pertumbuhan dan perkembangan pada periode perkembangan anak berikutnya (Dosman et al., 2012). Apabila terjadi gangguan tumbuh kembang pada masa balita maka akan berdampak pada masa selanjutnya (Kesehatan \& Indonesia, 2017). Pertumbuhan anak yang sehat dipengaruhi oleh pengasuhan orang tua (Nur \& Adriani, 2009). Diperkirakan 1-3\% anak mengalami keterlambatan perkembangan usia $<5$ tahun dengan 5-10\% dalam 2 aspek perkembangan. Presentase gizi buruk di Jawa Timur tahun 2016 sebesar 2,6\% sedangkan gizi kurang sebesar $11 \%$ (RI, 2016).
Cakupan pemberian ASI Eksklusif tahun 2017 di Banyuwangi sebesar 74\% belum memenuhi target yang telah ditetapkan (77\%) (Jawa Timur, 2017). Pada tahun 2017 angka balita yang mengalami gizi buruk di Banyuwangi sebesar $0.55 \%$. Berdasarkan laporan Dinas Kesehatan Banyuwangi menunjukkan angka kematian bayi tahun 2017 sebanyak 111 setiap 1000 Kelahiran Hidup. Berdasarkan pemeriksaan KPSP didapatkan data tahun 2015 terdapat 10 anak mengalami keterlambatan perkembangan (Banyuwangi, 2018). Berdasarkan survei data awal didapatkan data jumlah persalinan di Ruang Bersalin RSU Blambangan Banyuwangi Bulan Januari-Juli 2018 terdapat 502 persalinan dengan rata-rata 
83 persalinan setiap bulan dan semua ibu yang melahirkan belum pernah diberikan anticipatory guidance.

Kehidupan awal anak dimulai dari orang tua, sehingga orang tua bertanggung jawab terhadap masa depan anak (Hasinuddin, 2010). Setiap orang tua memanfaatkan pendidikan kesehatan untuk mendapatkan informasi tentang bagaimana mengasuh anak (Thygesen et al., 2017). Konseling oleh petugas kesehatan dapat mengurangi perilaku ibu pengenalan dini makanan padat pada bayi $(<6$ bulan) (Kuo et al., 2011). Anticipatory guidance adalah metode pendidikan yang disediakan untuk memberikan bimbingan kepada orang tua baru sehingga anak tumbuh dan berkembang optimal. Seorang anak sangat membutuhkan aktivitas bermain yang akan mempermudah perkembangan kognisi anak (Wilujeng, 2018). Sebagai bagian dari tenaga kesehatan profesional, perawat mempunyai peran yang penting dalam membantu memberikan bimbingan dan pengarahan pada orang tua (Dosman et al., 2012). Keluarga membutuhkan panduan tentang pentingnya memberikan stimulasi perkembangan pada anak (Pediatrics, 2016). Dengan mengetahui masalah perkembangan sejak dini, anak-anak dapat diberikan perawatan yang lebih efektif, sehingga defisit perkembangan lebih lanjut dapat dicegah (Moodie et al., 2014). Banyak data yang menunjukkan pentingnya bimbingan orang tua dalam mengasuh anak sampai usia remaja (Partridge, 2014). Pemberian anticipatory guidance akan efektif apabila diberikan dalam bentuk pelatihan menggunakan buku panduan. Pada penelitian ini peneliti menggunakan buku pegangan fasilitator kelas ibu balita serta buku KIA yang dimiliki oleh ibu.

\section{METODE}

Penelitian ini menggunakan quasi experimental post test only non equivalent control group. Variabel bebas penelitian ini adalah anticipatory guidance. Variabel terikatnya adalah perilaku ibu dalam stimulasi tumbuh kembang. Pada kelompok perlakuan dilakukan pemberian anticipatory guidance selama 5 kali pertemuan menggunakan buku pegangan fasilitator kelas ibu balita terdiri dari Modul A1: pemberian ASI, modul A2 : Pemberian Imunisasi, modul A3 : Pemberian MP-ASI, modul A4 : Tumbuh kembang bayi dan modul A5 : Penyakit terbanyak pada bayi. Instrumen yang digunakan untuk menilai perilaku ibu dalam stimulasi tumbuh kembang adalah kuesioner. Analisis bivariat yang dilakukan pada penelitian ini adalah : Uji statistik $U$ Mann-Whitney untuk mengetahui apakah ada perbedaan perilaku ibu dalam stimulasi tumbuh kembang pada kelompok kontrol maupun intervensi.

Pengambilan data pada penelitian ini dilakukan di Ruang Bersalin RSD Blambangan Banyuwangi 2019 ditindaklanjuti dengan melakukan kunjungan ke rumah masingmasing responden

\section{HASIL}

Tabel 1 Distribusi usia ibu di Ruang Bersalin RSD Blambangan Banyuwangi 2019.

\begin{tabular}{cccc} 
No. & $\begin{array}{c}\text { Usia Ibu dalam } \\
\text { tahun }\end{array}$ & n & \% \\
\hline 1. & $20-25$ & 16 & 30 \\
\hline 2. & $26-30$ & 21 & 39 \\
\hline 3. & $31-35$ & 7 & 12 \\
\hline 4. & $36-40$ & 10 & 19 \\
\hline & Total & 54 & $100 \%$
\end{tabular}

Sumber : (Data Primer, 2019)

Tabel 2 Pendidikan ibu di Ruang Bersalin RSD Blambangan Banyuwangi 2019

No. Pendidikan Ibu $\quad$ n $\%$

\begin{tabular}{cccc}
\hline 1 & SD & 2 & 4 \\
\hline 2 & SMP & 1 & 2 \\
\hline 3 & SMA & 49 & 90 \\
\hline 4 & $\begin{array}{c}\text { Perguruan } \\
\text { Tinggi }\end{array}$ & 2 & 4 \\
\hline & Total & 54 & $100 \%$ \\
\hline
\end{tabular}

Sumber : (Data Primer, 2019) 
Tabel 3 Pekerjaan ibu di Ruang Bersalin RSD Blambangan Banyuwangi 2019.

\begin{tabular}{lccc} 
No. & Pekerjaan Ibu & n & \% \\
\hline 1 & IRT & 43 & 80 \\
\hline 2 & SWASTA & 9 & 16 \\
\hline 3 & PNS & 1 & 2 \\
\hline 4 & Guru & 1 & 2 \\
\hline & Total & 54 & $100 \%$
\end{tabular}

Sumber : (Data Primer, 2019)

Tabel 9 Hasil Uji Normalitas perilaku ibu dalam stimulasi tumbuh kembang bayi usia 0-6 bulan di Rumah Sakit Umum Blambangan Banyuwangi 2014

\begin{tabular}{ccccccc} 
& \multicolumn{2}{c}{$\begin{array}{c}\text { Kolmogorov- } \\
\text { Smirnov }\end{array}$} & \multicolumn{3}{c}{ Shapiro-Wilk } \\
\cline { 2 - 7 } $\begin{array}{c}\text { Kelom } \\
\text { pok }\end{array}$ & $\begin{array}{c}\text { Statisti } \\
\text { c }\end{array}$ & df & Sig & $\begin{array}{l}\text { Statisti } \\
\text { c }\end{array}$ & $\begin{array}{c}\text { d } \\
\text { f }\end{array}$ & Sig \\
\hline \multirow{2}{*}{$A G$} & 0,495 & 2 & 0,00 & 0,476 & 2 & 0,0 \\
& & 7 & 0 & & 00 \\
\hline \multirow{2}{*}{ Kontrol } & 0,423 & 2 & 0,00 & 0,597 & 2 & 0,0 \\
& & 7 & 0 & & & 0 \\
\hline
\end{tabular}

Pada tabel 9 di atas menunjukkan bahwa hasil uji normalitas pada variabel perilaku ibu dalam stimulasi tumbuh kembang usia 0-6 bulan menggunakan metode Lilliefors dan Shapiro Wilk. Nilai Sig ( $p$ Value) kedua uji di atas $<0,05$ yang berarti data tidak berdistribusi normal sehingga peneliti memilih menggunakan Mann Whitney U Test.

Tabel 10 Perbedaan perilaku ibu dalam stimulasi tumbuh kembang bayi usia 0-6 bulan di Rumah Sakit Umum Blambangan Banyuwangi 2014

\begin{tabular}{|c|c|c|c|c|c|}
\hline \multicolumn{2}{|c|}{ Perlakuan } & \multicolumn{3}{|c|}{ Kontrol } & \multirow{2}{*}{$\begin{array}{c}\text { Sig } \\
(2- \\
\text { taile } \\
d)\end{array}$} \\
\hline $\begin{array}{c}\text { Mea } \\
n \\
\text { Rank }\end{array}$ & $\begin{array}{c}\text { Sum } \\
\text { of } \\
\text { Ranks }\end{array}$ & $\begin{array}{c}\text { Mann- } \\
\text { Whitne } \\
\text { yU }\end{array}$ & $\begin{array}{c}\text { Mea } \\
n \\
\text { Rank } \\
\end{array}$ & $\begin{array}{c}\text { Sum } \\
\text { of } \\
\text { Ranks }\end{array}$ & \\
\hline $\begin{array}{c}21,0 \\
0\end{array}$ & $\begin{array}{c}567,0 \\
0\end{array}$ & 189,00 & $\begin{array}{c}34,0 \\
0\end{array}$ & $\begin{array}{c}918 \\
00\end{array}$ & $\begin{array}{c}0,00 \\
0\end{array}$ \\
\hline
\end{tabular}

Berdasarkan tabel 10 menunjukkan bahwa pada variabel perilaku ibu dalam stimulasi tumbuh kembang yang diberikan intervensi anticipatory guidance dan kelompok kontrol dengan hasil Sig (2-tailed) 0,000< 0,05 yang artinya ada perbedaan perilaku ibu dalam stimulasi tumbuh kembang yang diberikan anticipatory guidance dengan ibu tidak diberikan anticipatory guidance.

\section{PEMBAHASAN}

Pencapaian derajat kesehatan yang tinggi bagi anak adalah sebagai satu bagian dari system pelayanan kesehatan di keluarga. Keluarga sebagai suatu kehidupan yang konstan dan individu mendukung, menghargai dan meningkatkan kekuatan dan kompetensi dalam memberikan asuhan terhadap anak, sedangkan prinsip keperawatan anak harus berfokus pada anak dan keluarga, untuk memenuhi kebutuhan anak dan keluarga (Setyawan, 2017). Memiliki bayi yang baru lahir adalah momen belajar bagi seorang ibu yang akan merubah pola hidup dan kebiasaan sehari-hari demi kesehatan bayinya (French et al., 2012). Kemajuan terbesar akan terjadi ketika langkahlangkah perkembangan sosial dan emosional balita dibuat dengan jelas (Jones et al., 2016). Kehidupan awal anak dimulai dari orang tua, sehingga orang tua bertanggung jawab terhadap masa depan anak (Hasinuddin, 2010). Setiap orang tua memanfaatkan pendidikan kesehatan untuk mendapatkan informasi tentang bagaimana mengasuh anak (Thygesen et al., 2017). Konseling oleh petugas kesehatan dapat mengurangi perilaku ibu dalam pemberian makanan dini pada bayi usia kurang dari 6 bulan (Kuo et al., 2011). Anticipatory guidance adalah metode pendidikan yang disediakan untuk memberikan bimbingan kepada orang tua baru sehingga anak tumbuh dan berkembang optimal. Stimulasi yang tepat akan merangsang otak balita sehingga perkembangan kemampuan gerak, bicara dan bahasa, sosialisasi dan kemandirian pada balita berlangsung optimal sesuai dengan umur anak. Deteksi dini penyimpangan tumbuh kembang perlu dilakukan untuk dapat mendeteksi secara dini adanya penyimpangan tumbuh kembang balita termasuk menindaklanjuti setiap keluhan orang tua terhadap masalah tumbuh kembang anaknya. 
Berdasarkan penelitian yang dilakukan oleh (Reich \& Bickman, 2010) menunjukkan bahwa kelompok ibu yang diberikan buku cara mendidik anak memiliki pengetahuan yang lebih tinggi dari pada 2 kelompok yang lain. Sehingga dapat disimpulkan buku yang dibaca ibu tampak efektif dalam memberikan bimbingan antisipatif. Orang tua melaporkan perlunya pelatihan dan dukungan tambahan untuk membuat bimbingan antisipatif lebih efektif. Anticipatory guidance yang terdiri dari informasi yang bermanfaat, untuk memberikan dukungan kepada orang tua dalam pengambilan keputusan sehingga meningkatkan praktik pengasuhan (Sege et al., 2006).

Intervensi berbasis masyarakat mempengaruhi pertumbuhan anak. (Blake-lamb et al., 2016). Anticipatory guidance diberikan dengan harapan bahwa orang tua terlibat dalam mendukung perilaku kesehatan anak dan perkembangan awal anak (Wilujeng et al., 2020). Orang tua dapat dengan mudah diajari metode meningkatkan disiplin dan pencegahan cedera pada anak. Lebih dari $99 \%$ orang tua melaporkan kegiatan saat ini mendukung perkembangan anak mereka (Combs-orme et al., 2015). AAP merekomendasikan pelatihan pediatrik bagi ibu baru dan calon pengasuh anak selama 3 bulan (Mccolgan et al., 2010). Studi secara epidemiologi, sosiologis, dan genetik telah semakin menunjukkan korelasi antara pola asuh orang tua dengan kesehatan anak, dan pentingnya family centered care untuk kesehatan anak. Sering kali informasi tentang kesehatan anak menjadi efektif apabila disampaikan kepada keluarga sehingga keluarga telah menjadi mitra sejak awal bagi tenaga kesehatan demi tercapainya anak yang sehat (VICTOR C. STRASBURGER, 2010). Alat dan bahan yang dibutuhkan peneliti meliputi bloknote dan bolpoint untuk responden, buku kelas ibu balita, buku KIA serta pantom payudara sehingga diharapkan responden lebih mudah memahami materi yang disampaikan. Anticipatory guidance disampaikan dalam bentuk penyuluhan, diskusi dan simulasi.

Pemberian anticipatory guidance dilakukan di beberapa rumah bidan dan kader sebagai tempat berkumpulnya responden. Penyampaian materi masing-masing modul dilakukan dengan durasi 30 menit dilanjutkan dengan diskusi. Pada saat sesi tanya jawab diskusi berjalan dengan interaktif hal ini tampak dari banyaknya ibu-ibu yang mengajukan pertanyaan tentang pertumbuhan dan perkembangan bayi kepada para peneliti. Proses penyampaian modul dilakukan selama 3 bulan. Pada bulan pertama dilakukan penyampaian modul pemberian ASI dan modul tumbuh kembang bayi, pada bulan kedua adalah penyampaian modul imunisasi dan penyakit terbanyak pada bayi selanjutnya penyampaian modul pemberian MP-ASI dilakukan pada bulan ketiga. Setelah itu peneliti melakukan penilaian pertumbuhan dan perkembangan bayi dengan menggunakan buku KIA dan KPSP (Kuesioner Pra Skrining Perkembangan). Adanya perbedaan pertumbuhan dan perkembangan bayi yang diasuh oleh ibu yang telah diberikan pendampingan anticipatory guidance dibandingkan dengan ibu yang tidak diberikan anticipatory guidance, dalam hal ini ibu yang telah diberikan pendampingan anticipatory guidance telah mendapat informasi yang lebih jelas mengenai pertumbuhan dan perkembangan bayi melalui pemberian materi dari 5 modul yang terdapat dalam buku pegangan fasilitator kesehatan ibu dan balita yang terdiri dari pentingnya pemberian ASI eksklusif bagi bayi mengingat zat gizi yang terkandung dalam ASI merupakan komponen zat gizi yang sangat lengkap dan sesuai dengan pencernaan bayi selain itu ASI juga mengandung zat anti bodi yang sangat penting untuk meningkatkan daya tahan tubuh bayi sehingga bayi tidak mudah sakit. Pemberian ASI saja pada bayi selama 6 bulan pertama bukan merupakan sesuatu yang mudah bagi ibu-ibu yang belum memahami manfaat dan pentingnya ASI terutama bagi ibu-ibu yang bekerja namun pada penelitian ini sebagian besar responden adalah sebagai ibu rumah tangga sehingga dengan pendampingan anticipatory guidance tentang manfaat ASI eksklusif bagi bayi maka ibu-ibu banyak yang telah berhasil memberikan pemberian ASI saja pada bayinya sehingga bayi memiliki pertumbuhan yang baik, sedangkan pada modul pertumbuhan dan perkembangan bayi menekankan pemahaman mengenai pentingnya deteksi dini pertumbuhan bayi melalui pemeriksaan berat badan dan tinggi badan secara rutin setiap bulan di posyandu sehingga apabila ada penyimpangan pertumbuhan pada bayi dapat segera dilakuan intervensi. 


\section{KESIMPULAN DAN SARAN}

Berdasarkan hasil uji statistik dengan menggunakan uji Mann-Whitney $U$ pada variabel perilaku ibu dalam stimulasi tumbuh kembang yang diberikan intervensi anticipatory guidance dan kelompok kontrol dengan hasil Sig (2-tailed) 0,000 <0,05 yang artinya ada perbedaan perilaku ibu dalam stimulasi tumbuh kembang yang diberikan anticipatory guidance dengan ibu tidak diberikan anticipatory guidance. Pelayanan Kesehatan menyusun program untuk memberikan Pendidikan dan konseling kepada ibu-ibu yang baru melahrkan tentang optimalisasi pertumbuhan dan perkembangan.

\section{DAFTAR PUSTAKA}

Banyuwangi, D. K. (2018). Data seputar kesehatan.

https://www.banyuwangikab.go.id/

Blake-lamb, T. L., Locks, L. M., Perkins, M. E., Baidal, J. A. W., Cheng, E. R., \& Taveras,

E. M. (2016). Interventions for Childhood Obesity in the First 1,000 Days A Systematic Review. American Journal of Preventive Medicine, 1-10. https://doi.org/10.1016/j.amepre.2015.11. 010

Combs-orme, T., Nixon, B. H., \& Herrod, H. G. (2015). Anticipatory Guidance and Early Child Development: Pediatrician Advice, Parent Behaviors, and Unmet Needs as Reported by Parents From Different Backgrounds. https://doi.org/10.1177/000992281140330 2

Dosman, C., Faap, F., Andrews, D., \& Frcpc, F. (2012). Anticipatory guidance for cognitive and social- emotional development: Birth to five years. 17(2), 75-80.

French, G. M., Nicholson, L., Skybo, T., Klein, E. G., Schwirian, P. M., Murray-Johnson, L., Sternstein, A., Eneli, I., Boettner, B., \& Groner, J. A. (2012). An Evaluation of Mother-Centered Anticipatory Guidance to Reduce Obesogenic Infant Feeding Behaviors. Pediatrics, 130(3), e507-e517. https://doi.org/10.1542/peds.2011-3027

$\begin{array}{cr}\text { Hasinuddin, M. (2010). } & \text { MODUL } \\ \text { ANTICIPATORY } & \text { GUIDANCE } \\ \text { TERHADAP PERUBAHAN POLA ASUH }\end{array}$

ANAK ( Anticipatory Guidance Module Changes the Authoritaritative Parenting of Parents in Stimulating Children Development ). 51-58.

Jawa Timur, D. (2017). PROFIL KESEHATAN PROVINSI JAWA TIMUR TAHUN 2016. In Dinkes Jawa Timur.

Jones, S. M., Zaslow, M., Darling-churchill, K. E., \& Halle, T. G. (2016). Journal of Applied Developmental Psychology Assessing early childhood social and emotional development : Key conceptual and measurement issues. Journal of Applied Developmental Psychology, 45, 42-48.

https://doi.org/10.1016/j.appdev.2016.02. 008

Kesehatan, K., \& Indonesia, R. (2017). PROFIL KESEHATAN INDONESIA 2016.

Kuo, A. A., Inkelas, M., Slusser, W. M., Maidenberg, M., \& Halfon, N. (2011). Introduction of Solid Food to Young Infants. $1185-1194$. https://doi.org/10.1007/s10995-0100669-5

Mccolgan, M. D., Cruz, M., Mckee, J., Dempsey, S. H., Davis, M. B., Barry, P., Lisa, A., \& Giardino, A. P. (2010). Child Abuse \& Neglect Results of a multifaceted Intimate Partner Violence training program for pediatric residents $\square$. Child Abuse \& Neglect, 34(4), 275283.

https://doi.org/10.1016/j.chiabu.2009.07. 008

Moodie, S., Daneri, P., Goldhagen, S., Tamara, H., Green, K., \& LaMonte, L. (2014). EARLY CHILDHOOD DEVELOPMENTAL SCREENING: A COMPENDIUM OF MEASURES FOR CHILDREN AGES BIRTH TO FIVE Early Childhood Developmental Screening : OPRE CHILD TRENDS.

Nur, F., \& Adriani, M. (2009). Hubungan Pola Asuh , Asih, Asah dengan Tumbuh Kembang Balita Usia 1-3 Tahun.

Partridge, B. (2014). Adolescent Pediatric Decision-Making: A Critical Reconsideration in the Light of the Data. 299-308. https://doi.org/10.1007/s10730014-9250-8

Pediatrics, A. A. O. (2016). The Pediatricians Role in Optimizing School Readiness. 
Pediatrics, $\quad$ 138(3), $\quad$ e20162293e20162293.

https://doi.org/10.1542/peds.2016-2293

Reich, A. S. M., \& Bickman, L. (2010). The Effectiveness of Baby Books for Providing Pediatric Anticipatory Guidance to New Mothers. 125(5), 997-1002. https://doi.org/10.1542/peds.2009-2728

RI, K. K. (2016). PROFIL KESEHATAN INDONESIA TAHUN 2015. Kementerian Kesehatan RI.

Sege, R. D., Hatmaker-flanigan, E., Vos, E. De, Levin-goodman, R., \& Spivak, H. (2006). Anticipatory Guidance and Violence Prevention: Results From Family and Pediatrician Focus Groups. 117(2). https://doi.org/10.1542/peds.2005-0377

Setyawan, A. B. (2017). Hubungan antara berat bayi lahir rendah dengan tumbuh kembang anak usia dini.

Thygesen, L. C., Koushede, V., Sjo, C., Axelsen, F., Winkel, P., Lindschou, J., Gluud, C., \& Due, P. (2017). Antenatal small-class education versus auditorium- based lectures to promote positive transitioning to parenthood $-A$ randomised trial. 1-18. https://doi.org/10.1371/journal.pone.0176 819

VICTOR C. STRASBURGER, md. (2010). P ERFORMING PREVENT IVE S ERVICE S: A BRIGHT FUTURE S HANDBOOK. In CHILDREN, ADOLESCENTS, AND MEDIA (p. 164).

Wilujeng, A. P. (2018). Pengaruh Brain Gym Terhadap Kadar Kortisol Selama Hospitalisasi Pada Anak Usia Pra Sekolah. 3(109), 117.

Wilujeng, A. P., Trianita, D., \& Indriani, N. (2020). Jurnal Keperawatan Muhammadiyah Pengaruh Anticipatory Guidance Terhadap Pertumbuhan Dan Perkembangan Bayi Usia 0-6 Bulan. 5(1), $11-18$ https://doi.org/http://dx.doi.org/10.30651/ jkm.v5il.3325 